\title{
Photochemistry and Beer
}

\author{
A. Vogler and H. Kunkely \\ Institut für Chemie, Universität Regensburg, D-8400 Regensburg, West Germany
}

Upon exposure to light, particularly sunlight, the taste of beer changes and becomes very offensive. This light sensitivity of beer is well known as "sun taste," "sun struck flavor," "light taste," or most generally "light struck flavor" (LSF) (1). This phenomenon has been a subject of considerable interest, speculation, and investigation. It is also of great economical importance. LSF was first mentioned in the literature by C. Lintner in a textbook of beer brewing in 1875 (4). During the last 100 years in many countries attempts have been made to understand LSF. It is interesting that some early observations on the light sensitivity of beer may be regarded as important in the history of photochemistry in general. We report on the history as well as the present knowledge of LSF. Our review was written for the benefit of those who are interested in photochemistry and beer.

\section{Effect of Bottle Color on LSF}

LSF develops when beer bottles are exposed to light for some time. Bottle glass transmits the light which is absorbed by beer causing LSF. By 1888 qualitative observations on the wavelength dependence of the photochemistry of beer had been made (5). It was found that the development of LSF depends on the glass color of beer bottles. In 1908 I. Brand discovered (6) that the same wavelengths of light which cause LSF also lead to the well-known photoredox decomposition of ferrioxalate which is the basis of the now famous Hatchard and Parker actinometer for the determination of absorbed light intensities (7):

$$
\begin{aligned}
\mathrm{Fe}(\mathrm{III})\left(\mathrm{C}_{2} \mathrm{O}_{4}\right)_{3}{ }^{3-} \stackrel{\mathrm{h} \nu}{\rightarrow} & \mathrm{Fe}(\mathrm{II}) \\
& +\left(\mathrm{C}_{2} \mathrm{O}_{4}\right)^{-}+2 \mathrm{C}_{2} \mathrm{O}_{4}{ }^{2-} \rightarrow \text { secondary reactions }
\end{aligned}
$$

While the photochemical formation of $\mathrm{Fe}$ (II) is now measured by spectrophotometric determination of the 0 -phenanthroline complex of $\mathrm{Fe}(\mathrm{II})$, Brand added $\mathrm{Fe}(\mathrm{CN})_{6}{ }^{3-}$ and analyzed $\mathrm{Fe}$ (II) colorimetrically as Prussian Blue. He observed that under identical experimental conditions Prussian Blue was faster formed in green than in brown bottles. Consequently, Brand recommended the use of brown bottles for better light protection of beer. It is now well known that the light sensitivity of beer extends from the UV to about $500 \mathrm{~nm}(2,3)$. Looking at the absorption spectra (Fig. 1) it is quite obvious why brown bottles are better than green bottles. While green glass transmits some light of the wavelengths 400 to $500 \mathrm{~nm}$, brown glass cuts off most of it. The influence of glass color on the development of LSF has been confirmed many times $(2$, 3 ) after the original work of Brand. These observations had a great economical significance. Green bottles are now only rarely used for the storage of beer. One of the authors (A. V.) still remembers the 1950's when construction workers, who often store their beer outdoors, rejected beer in green bottles.

\section{Organoleptic Analysis of LSF}

While all means of classical chemical or modern spectroscopic analyses are used for the identification and quantitative determination of the products of a photochemical reaction, the development of LSF is by definition analyzed by experts in beer tasting (organoleptic analysis). To get reliable results, panels of up to 25 beer tasters are used as the analytical tool $(8,9)$. The larger the number, the smaller the error introduced by those beer tasters who are in a bad shape during the ana-

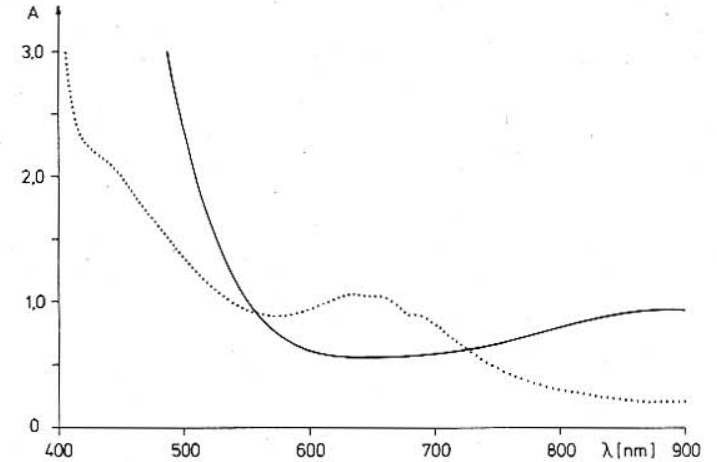

Figure 1: Absorption spectra of brown (-) and green $(\cdots \cdots)$ beer bottle glass; thickness $0.3 \mathrm{~cm}$.

lyzing beer drinking procedure. The reason that manpower has not yet been replaced by gas chromatography or spectrophotometry (analyses) lies in the uncertain origin of LSF $(3,9)$. Although the photochemistry of some components of beer has been investigated, an unambigous identification of the photoproducts causing LSF has not yet been achieved. The human sense of taste, particularly that of trained beer drinkers, seems to be an extremely sensitive and selective detector for the offensive compounds causing LSF. Chemical and physical analysis may be hampered by the difficulty to identify the offensive compounds in very low concentrations in the presence of a large variety of other compounds occurring in beer.

\section{Photochemistry of Beer}

Despite the long history of LSF, not very much is known about the photochemistry involved in the formation of LSF. Some of the reasons for this lack are outlined above. In addition, it is very likely that a variety of photochemical reactions take place in a solution which contains as many compounds as beer does. Some other photoreactions of beer which are not related to LSF are described below. But our attention has been drawn essentially to the formation of LSF, because it deteriorates the taste of beer. This reaction may be of minor importance with regard to other photochemical reactions which do, however, not affect the beer quality.

\section{(A) Origins of LSF}

There is convincing evidence $(3,9,10,11)$ that LSF is associated with the presence of the so-called iso- $\alpha$-acids (1) in beer (12).

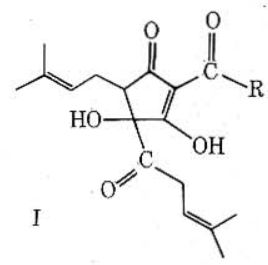

Iso-humulone $\left[\mathrm{R}=-\mathrm{CH}_{2} \mathrm{CH}\left(\mathrm{CH}_{3}\right)_{2}\right]$ is the most prominent representative of the iso- $\alpha$-acids (12) which are the basis of the typical beer flavor and called the "bittering principle" of beer (9). The iso- $\alpha$-acids are formed by a rearrangement of the $\alpha$-acids (2) during the boiling of wort in the beer brewing process. 


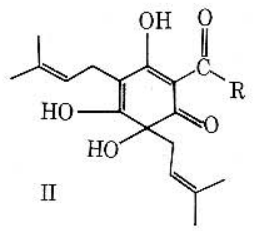

The $\alpha$-acids are the most important constituents of hops. Only the presence of the iso- $\alpha$-acids but not of other hops components is apparently responsible for the development of $\operatorname{LSF}(3,9,10,11)$. The unsaturated iso-hexenoyl side chain of the iso- $\alpha$-acids seems to play an important role. LSF does not develop when this unsaturated side chain of the iso$\alpha$-acids is hydrogenated catalytically or by $\mathrm{NaBH}_{4}(9,11)$. To prevent LSF this hydrogenation is carried out at an industrial scale for the production of an American beer (13). This beer is sold even in almost colorless bottles, probably for marketing reasons (14). Such a chemical treatment is forbidden in $\mathrm{Ba}$ varia. The very old (1516) law of purity does not allow the addition of anything but water, malt, hops, and yeast for beer brewing.

Although the photochemistry of the iso- $\alpha$-acids has not been investigated in any detail, it has been shown that its photolysis leads to the formation of 2-methylbutene-2 $(11,15)$. The isohexenoyl side chain is apparently the origin of the photochemical formation of the olefin. There is, however, nothing known, about the nature of the electronically excited state of iso- $\alpha$-acids or the mechanism by which the cleavage of the side chain occurs yielding finally the olefin.

But since both photochemical processes, the formation of LSF and 2- methylbutene-2, require the presence of the isohexenoyl side chain of the iso- $\alpha$-acids it was assumed that this olefin or a 2-methylbutene-2-ylradical, formed as a precursor of the olefin, leads in a secondary reaction to the compound causing $\operatorname{LSF}(3,10,11)$. This radical was thought to be formed by a homolytic cleavage of the side chain according to

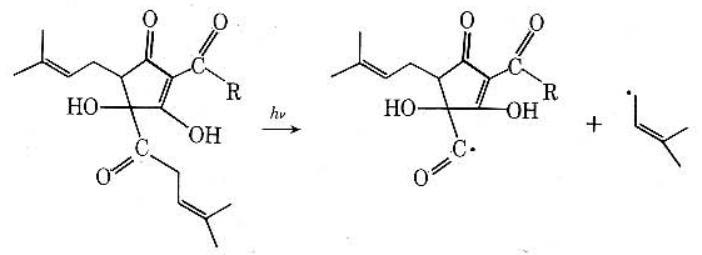

Again, any experimental evidence for the occurrence of such a radical is missing.

The iso- $\alpha$-acids are certainly not the only compounds necessary for the formation of LSF. Since 1941 (16) evidence has been accumulated that sulfur containing compounds, possibly cystine and others, which are always present in beer, are required for the development of $\operatorname{LSF}(2,3,10,17,18)$. The offensive flavor may then be due to the formation of thiols which are well known for their bad odor. It has been suggested that LSF is caused by 3-methyl-2-butene-1-thiol which is formed by the reaction of the 2-methylbuten-2-ylradical (see above) with sulfur compounds (10). But there is no obvious mechanism for this reaction. The presence of this specific thiol as origin of LSF has been disputed $(3,9)$. A Belgian taste panel of 10 persons decided that LSF is different from the flavor of beer to which synthetic 3-methyl-2-butene-1-thiol was added (9).

\section{(B) Spectroscopy and Primary Photoprocesses}

Although the iso- $\alpha$-acids participate in the formation of LSF it seems doubtful that they are the actual light absorbing species. The iso- $\alpha$-acids occur as two stereoisomers (12). Both are formed during the boiling of wort. From isohumulone, the most important iso- $\alpha$-acid, only the trans isomer was obtained as a pure material while the purification of the cis form which is an oil has not yet been achieved (9). Trans isohumulone, which has been shown to cause LSF (9), is a white crystalline solid which does not absorb at wavelengths longer than 350

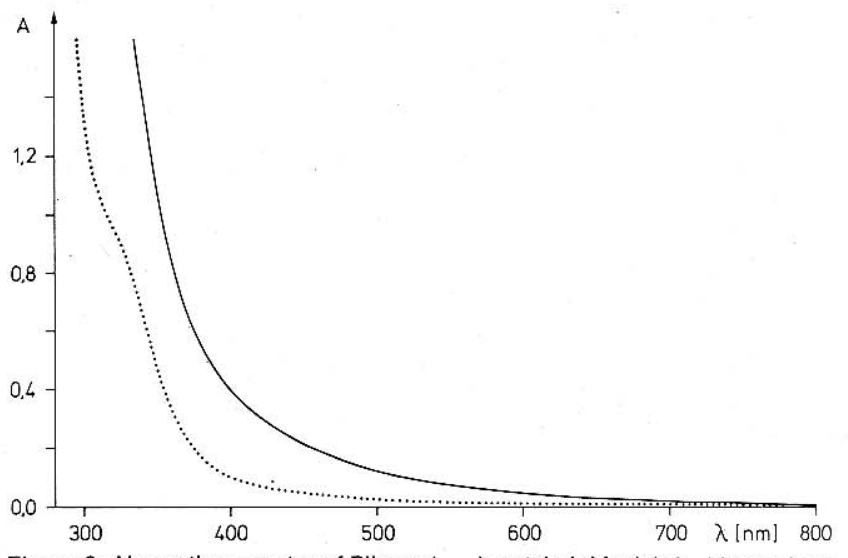

Figure 2: Absorption spectra of Pilsner $(\cdots \cdots)$ and dark Munich $(-)$ beer, $1 \mathrm{~cm}$ cells.

$\mathrm{nm}$ (19). Since LSF is caused also by visible light down to 500 $\mathrm{nm}$, other dyes which are the origin of the beer color, should absorb the light, causing LSF. This assumption is supported by the early observations of Brand (6). He found that dark Munich beer is more susceptible to the formation of LSF than light Pilsner beer. The color of dark beer, which absorbs more light in the visible region than light beer (Fig. 2), is due to special malt and not hops. It has been suggested that riboflavin (17) or other dyes, based on malt (20), are the actual light absorbing species which sensitize the formation of LSF. Electronically excited $(*)$ dyes may transfer the excitation energy (21) to iso- $\alpha$-acids which react photochemically leading to LSF

$$
\begin{gathered}
\text { dye } \stackrel{\mathrm{h} \nu}{\rightarrow} \text { dye* } \\
\text { dye }^{*}+\text { iso- } \alpha \text {-acid } \rightarrow \text { dye }+ \text { iso- } \alpha \text {-acids } * \\
\text { iso- } \alpha \text {-acids* } \rightarrow \text { photochemical reaction } \rightarrow \text { LSF }
\end{gathered}
$$

However, it is not clear if the threshold energy for the formation of LSF, corresponding to light of $500 \mathrm{~nm}$, is sufficient to populate reactive excited states of the iso- $\alpha$-acids by energy transfer.

Alternatively, the formation of LSF may not involve at all a photochemical reaction of the iso- $\alpha$-acids. It is also feasible that the absorbing pigments undergo any photoreaction yielding reactive intermediates which attack the iso- $\alpha$-acids in secondary thermal reactions leading finally to the formation of LSF.

In this context it is of some interest that the presence of oxygen prevents LSF $(2,8)$. Oxygen could quench excited states or scavenge photochemical intermediates. It is even possible that singlet $\mathrm{O}_{2}$ is produced by dye sensitization (22). Singlet $\mathrm{O}_{2}$ reacts selectively with the bitter components of hops producing compounds which are also bitter (23). However, $\mathrm{O}_{2}$ cannot be used to avoid LSF since it deteriorates the beer quality and shortens the storage time of beer considerably when kept in the dark.

\section{(C) Additional Photoreactions}

Although probably not relevant to the development of LSF the photochemistry of the two most important constituents of hops, the $\alpha$-and $\beta$-acids should be mentioned here. While the $\beta$-acids can be present in beer in considerable amounts, the $\alpha$-acids are converted to the iso- $\alpha$-acids to the largest part during the wort boiling process (12).

Humulone (1), an $\alpha$-acid, undergoes a clean photorearrangement $(19,24)$ to the trans form of isohumulone $(2)$, while the thermal reaction (wort boiling) yields the trans and cis isomer (12) which are both equally bitter (9). The photoconversion occurs regio and stereospecific with a quantum yield of 0.48 at $350 \mathrm{~nm}$ exciting wavelength (25).

Lupulone and colupulone, which are members of the $\beta$-acid (3) (12), undergo a photoelimination of isoprene with aromatization of the six-membered ring $(26,27)$. 
<smiles>[R]C(=O)c1c(O)c(CC=C(C)C)c(O)c(CC=C(C)C)c1O</smiles>

III

\section{Conclusions}

The reader, who is interested in photochemistry, may not be completely satisfied, since many questions remain open. On the other side, the reader who is more interested in beer drinking can benefit from the following recommendations: Unless one prefers beer from barrels or cans it is recommended to buy it in brown bottles. If the favorite beer comes in green bottles they should be stored in the dark. Even beer in brown bottles should not be exposed to light for longer storage. When beer is offered in colorless bottles one has not to worry at all because chemistry made this beer light resistant.

Stimulating discussions and especially helpful comments from Dr. H. G. Klose are greatly appreciated.

\section{Literature Cited}

(1) For reviews see refs. (2) and (3).
(2) Lüers, H., Brauwelt, 95, 582 (1955).

(3) Späth, G., Niefind, H. J., and Martina, M., Monatsschr. Brauerei, 28, 73 (1975).

(4) Lintner, C., Lehrbuch der Bierbrauerei, Verlag Vieweg und Sohn, Braunschweig, 1875.

(5) Schultze, Allgem. Zeitschr. Bierbraurei und Malzfabrikation, 593 (1888).

(6) Brand, J., Zeitschr. ges. Brauwesen, 31, 333 (1908).

(7) Hatchard, C. G., and Parker, C. A., Proc. Roy. Soc., A235, 518 (1956).

(8) Krauss, G. and Schilfarth, H., Tagesztg. Brauerei, 61, 680 (1964); Brauwelt, 104, 1574 (1964).

(9) Verzele, M., Jansen, H. E., and Ferdinandus, A., J. Inst. Brewing, 76, 25 (1970).

(10) Kuroiwa, Y. and Hashimoto, N., Proc. Amer. Soc. Brewing Chemists, 28 (1961).

(11) Nakayama, T. O. M. and Fly, W. H. Proc. Amer. Soc. Brewing Chemists, 198 (1968).

(12) For a review on the chemistry of hops constituents see Stevens, R., Chem. Rev., 67, 19 (1967)

(13) Hougen, O.A. U.S. Patent 3.079,262; Chem. Abstr, 58, 10696a (1963). For further information see refs. (9) and (12) (p. 36).

(14) An editorial, Brauwelt, 106, 768 (1966).

(15) Zenz, H., Proc. Europ. Brew. Conv., 14th Congr., Salzburg, 1973, Elsevier Amsterdam, 1974, p. 419. See also Brauwissenschaft, 27, 261 (1974); 28, 184 (1975).

(16) Gray, P. P., Stone, J., and Rothchild, H., cited in Ref. Wochenschrift Brauerei, 209 (1941).

(17) Yamanishi, T., and Obata, Y., Bull. Chem. Soc. Japan, 22247 (1949) and 23, 125 (1950)

(18) Obata, Y. and Ishikawa, Y., Nature, 205, 75 (1965).

(19) Klose, H. G., Dissertation, Techn. Hochscule Munich, 1966.

(20) Jakobsen, B. and Högberg, B., cited in ref. (2).

(21) Legg, K. D., J. CHEM. EdUC. 50, 848 (1973).

(22) Bland, J., J. CHEM. EDUC, 53, 274 (1976).

(23) De Keukeleire, D., Siaens, E., and Verzele, M., Bull. Soc. Chim. Belg., 85, 293 (1976).

(24) Clarke, B. J., and Hildebrand, R. P., J. Inst. Brewing, 71, 26 (1965).

(25) DeKeukeleire, D. and Blondeel, G. M., Tetrahedron Letters, 1343 (1979).

(26) Kühn, W., Dissertation, Technische Hochschule Munich, 1963.

(27) Fernandez, C. M., Chem. Comm., 1212 (1967). 